\title{
Adherence to growth hormone (GH) therapy in naïve to treatment GH-deficient children: data of the Italian Cohort from the Easypod Connect Observational Study (ECOS)
}

\author{
C. Centonze ${ }^{1} \cdot$ C. Guzzetti ${ }^{2} \cdot$ G. Orlando ${ }^{1} \cdot$ S. Loche ${ }^{2}$ on behalf of the Italian ECOS Investigators
}

Received: 29 January 2019 / Accepted: 1 April 2019 / Published online: 9 April 2019

(c) The Author(s) 2019

\begin{abstract}
Background With the use of non-objective measurement, adherence to growth hormone (GH) therapy has been reported suboptimal in a large proportion of patients, and poor adherence has been shown to affect short-term growth response in patients receiving GH treatment.

Objective The Easypod ${ }^{\mathrm{TM}}$ electronic device allows objective measurement of adherence. In this study, we report 3-year prospective adherence data of the Italian cohort of naïve GH deficient (GHD) children extrapolated from the Easypod Connect Observational Study (ECOS) database.

Patients and methods Seventy-three GHD children naïve to GH treatment were included in the analysis. 22 Italian centers participated in the study.

Results Mean adherence rate was consistently above $85 \%$ across the 3 -year observation period. Particularly, mean adherence was $88.5 \%, 86.6 \%$, and $85.7 \%$ after 1,2 and 3 years, respectively. Mean $( \pm$ SD) height-SDS increase after the first year was $0.41( \pm 0.38)$.

Conclusions The majority of naïve GHD children starting GH treatment with Easypod maintained an adherence rate $>85 \%$ up to 3 years. Easypod is a useful tool to follow-up patients' adherence allowing timely intervention to improve optimal treatment for these patients.
\end{abstract}

Keywords ECOS $\cdot$ Short stature $\cdot$ Children $\cdot$ Growth hormone $\cdot$ GHD

\section{Introduction}

Human recombinant growth hormone (h-rGH) is currently used to treat a variety of clinical conditions associated with short stature, including GH deficiency (GHD), Turner syndrome, Prader-Willi syndrome, children born small for gestational age (SGA), and children with chronic renal failure [1]. The growth response to GH therapy is influenced by a

The members of on behalf of the Italian ECOS Investigators listed in Acknowledgements.

\section{S. Loche}

Sandro.Loche@aob.it

1 Medical Affairs Department, Merck Serono S.p.A., Rome, Italy

2 SSD di Endocrinologia Pediatrica e, Centro Screening Neonatale, Ospedale Pediatrico Miccrocitemico "A. Cao", AO Brotzu, Via Jenner, 09121 Cagliari, Italy number of factors which include, among others, the initial diagnosis, the age of the patient, the dose of GH administered as well as individual responsiveness [2-4]. Although adherence to medication is a well-known clinical problem affecting several chronic diseases, measuring adherence is generally difficult and mostly based on patient self-reported questionnaires, prescription records, or vials counting [5]. With the use of non-objective measurement, adherence to GH therapy has been reported suboptimal in up to $77 \%$ of patients in different studies [6-12]. Poor adherence has been shown to be related to several factors including lower socioeconomic or educational status, injections considered difficult, lack of choice of injection device, use of conventional syringe rather than automatic pen injection device, and discomfort with injections [13]. Furthermore, poor adherence has been shown to affect short-term growth response in patients receiving GH treatment $[11,12,14]$.

The easypod ${ }^{\mathrm{TM}}$ electronic device allows objective measurement of adherence, and short-term studies have recently 
shown a good acceptance and adherence in patients taking h-rGH via this device [15-18]. Easypod allows transmission of injections' data (real time recorded dose and timing) by a wireless transmitter to physician, thus allows to examine individual patients' adherence remotely in real time settings. Easypod Connect Platform (ECP), as a whole, provides an e-health solution to improve patient management by remote examination and control of adherence to h-r.

The Easypod Connect Observational Study (ECOS) is a prospective international 5-year investigation designed to assess adherence to GH treatment in patients taking h-rGH via the Easypod device for several conditions. Data from this large international study including 1203 patients from 24 different countries have been recently published, and shown that median adherence rate in the entire cohort was maintained over $80 \%$ in the first 3 years, and declined thereafter [19]. This study has also reported adherence rate across the 5 -year observation period in the subgroup of naïve GHD patients of different ethnic origin, and shown that mean adherence rate in the first 2 years was $>80 \%$, and $>75 \%$ in the third year irrespective of the cause of GHD. In this study, we report 3-year prospective adherence data of the Italian cohort of naïve GHD children extrapolated from the ECOS database.

\section{Patients and methods}

Seventy-three GHD children naïve to GH treatment were recruited in 22 Italian centers and included in the analysis. Their main clinical characteristics are summarized in Table 1. The diagnosis of GHD was performed in each participating center according to standard endocrine practice. Seventy children had idiopathic GHD, two had organic GHD and one had congenital GHD. The study was approved by the local ethical committees, and written informed consent was obtained from the patients and/or from their legal

Table 1 Main clinical characteristics of the children studied

\begin{tabular}{ll}
\hline Age, years & \\
Mean (SD) & $9.78(3.20)$ \\
Median & 10.00 \\
Q1; Q3 & $8.00 ; 12.00$ \\
Min; max & $1.0 ; 15.0$ \\
Sex, $n(\%)$ & \\
Female & $35(47.9)$ \\
Male & $38(52.1)$ \\
Change in height SDS $(n=70)$ \\
Mean (SD) & $0.42(0.38)$ \\
Median & 0.41 \\
Q1; Q3 & $0.18 ; 0.61$ \\
\hline
\end{tabular}

guardians prior to their enrollment in the study. As reported in the large ECOS study [19], patients were enrolled in the database and after an initial baseline visit, they were seen 1-4 times/year. Adherence rate was derived from the Easypod device and calculated as the percentage of injections recorded versus prescribed.

\section{Results}

Adherence data were available for 65 patients after 1 year, for 40 patients after 2 years, and for 18 patients after 3 years (Fig. 1). Mean adherence rate was consistently above $85 \%$ across the 3-year observation period (Fig. 2). Particularly, mean adherence was $88.5 \%, 86.6 \%$, and $85.7 \%$ after 1,2 and 3 years, respectively. Mean adherence rate for individual treatment period (from the beginning of treatment to the last complete week of available data for each patient) was $86.51 \%$ (Fig. 2). Mean ( \pm SD) height-SDS increase after the first year was $0.41( \pm 0.38)$ (Table 1$)$. We found no significant correlation between the level of adherence and growth outcome after the first year of treatment.

\section{Discussion}

We have shown in this study that in the ECOS Italian cohort of GHD patients naïve to GH therapy the mean level of adherence is maintained $>85 \%$ for up to 3 years. The analysis of this subset of patients from a single country confirms the observation of the global ECOS data [19]. The recent large ECOS study has shown, in fact, that in naïve GHD patients, the adherence rate is maintained $>80 \%$ in the first 2 years, and declines thereafter. Of note, in the subset of patients of the italian cohort of this study, mean adherence rate was slightly better, and did not decline in the third year as in the large ECOS study, confirming our previous observation that children with GHD treated with $\mathrm{r}-\mathrm{hGH}$ via the

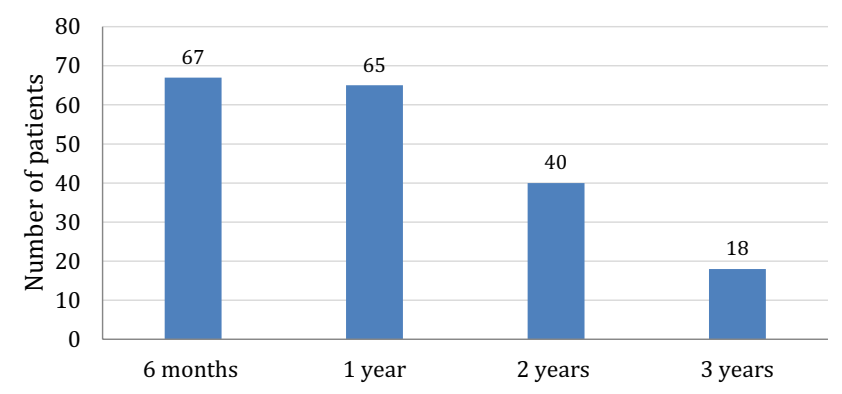

Fig. 1 Number of patients with prospective adherence data over the study period 
Fig. 2 Treatment adherence rates over time in the Easypod $^{\mathrm{TM}}$ adherence data analysis. Boxes show Q1 and Q3, with median as white line, and mean as red squares

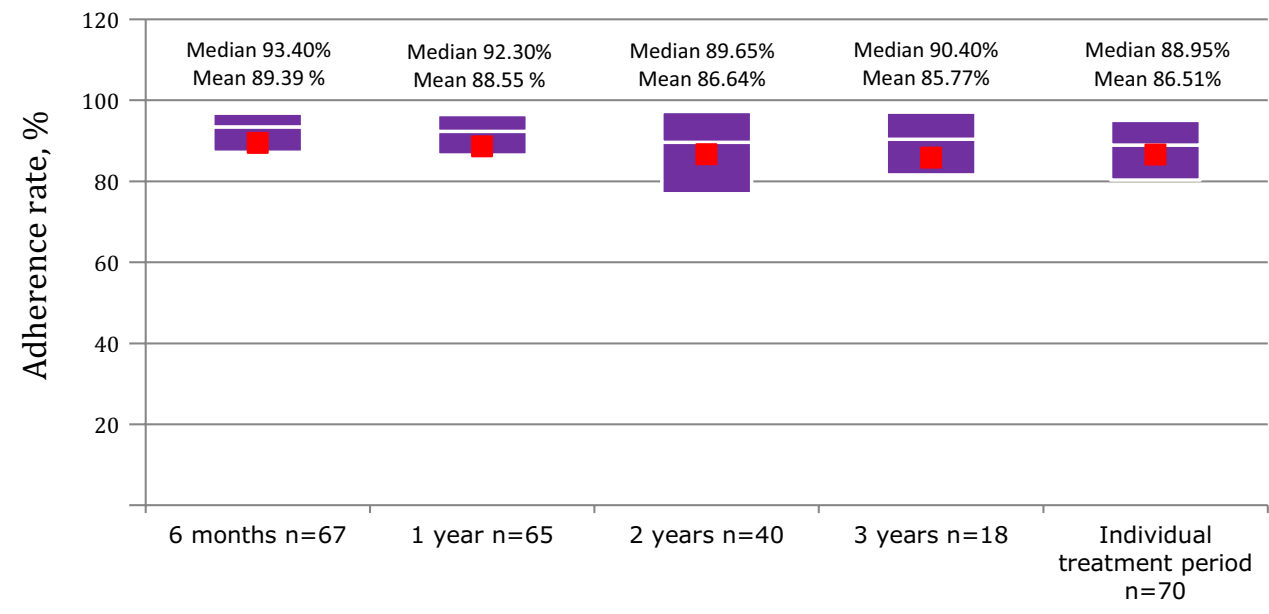

Easypod device generally have a good adherence to treatment [17]. In our previous short-term study, we recorded high levels of adherence in 97 patients taking r-hGH, with $57 \%$ of them having an adherence rate $>92 \%$. Other shortterm studies have confirmed good adherence in pediatric patients receiving h-rGH via the Easypod device, ranging from 87.5 to $99 \%[16-18,20]$.

In the present study, treatment was associated with the expected increase in height. The observed variability of the first year response is in line with previous findings obtained from analyses of large databases [21,22]. The variability of the growth response is a well known phenomenon, possibly related to the heterogeneity of patients in term of severity of GHD as well as individual responsiveness [3].

The diagnosis of growth hormone deficiency (GHD) is currently based on clinical and auxological assessment, with the supporting evidence from biochemical and MRI studies [23]. The diagnostic workup in a patient with suspected GHD includes evaluation of GH secretion by means of stimulation testing. The Italian Medicine Agency (AIFA) regulates the modalities of growth hormone prescription to GHD children, as well as the criteria for diagnosis [24]. Complying with the prescription criteria is mandatory for endocrinologists who can only prescribe GH within hospitals specifically accredited by government. Therefore, all GHD patients included in the ECOS in Italy fulfill the same national standards for diagnostic criteria. Furthermore, all patients of our study are of Caucasian origin. Based on these premises, our sample population can be considered homogeneous since our patients share the same endocrine phenotype as well as ethnic origin. In this regard, it should be pointed out that poor adherence has been correlated with ethnic origin [12] as well as with training by non-hospital staff or no training rather than training by hospital staff [6].

In short-term studies poor adherence has been shown to be related with the growth outcome $[11,12,14]$. The global ECOS study [19] has reported a positive correlation between adherence rate and growth response in the GHD patients. We found no correlation between the level of adherence and the growth outcome after the first year, possibly due to the small number of subjects and to the fact that adherence values were skewed toward high positive levels. Our results are in agreement with those recently reported by Van Dommelen et al. [25] who showed that average adherence in the first year was not associated with first year growth response in children with GHD but was highly correlated with growth response in the second year and 0-2 years in total.

In conclusion, we have shown that the majority of naïve GHD children starting GH treatment with Easypod in Italy maintained an adherence rate $>85 \%$ up to 3 years. Easypod is a useful tool to follow-up patients' adherence allowing timely intervention to improve optimal treatment for these patients.

Acknowledgements The members of on behalf of the Italian ECOS Investigators: C. Angeletti, F. Antoniazzi, S. Bernasconi, G.M. Cardinale, M. Caruso-Nicoletti, L Cavallo, S. Cianfarani, G. Citro, F. De Luca, S. Della Casa, M. Di Pietro, P. Garofalo, C. Giordano, N.A. Greggio, M.R. Licenziati, M. Maghnie, M. Parpagnoli, L. Persani, S. Pesce, M. Sacco, M. Salerno, L. Tafi.

\section{Compliance with ethical standards}

Conflict of interest Chiara Centonze and Giovanna Orlando are Employees of Merck Serono. Sandro Loche is member of the ECOS International Steering Committee and has received research support and lecture fees from Merck Serono.

Ethical approval The study was approved by the local ethical committees.

Informed consent Written informed consent was obtained from the patients and/or from their legal guardians prior to their enrollment in the study.

Open Access This article is distributed under the terms of the Creative Commons Attribution 4.0 International License (http://creativeco 
mmons.org/licenses/by/4.0/), which permits unrestricted use, distribution, and reproduction in any medium, provided you give appropriate credit to the original author(s) and the source, provide a link to the Creative Commons license, and indicate if changes were made.

\section{References}

1. Grimberg A, DiVall SA, Polychronakos C, Allen DB, Cohen LE, Quintos JB, Rossi WC, Feudtner C, Murad MH (2016) Guidelines for growth hormone and insulin-like growth factor-I treatment in children and adolescents: growth hormone deficiency, idiopathic short stature, and primary insulin-like growth factor-I deficiency. Horm Res Paediatr 86:361-397

2. Bang P, Ahmed SF, Argente J, Backeljauw P, Bettendorf M, Bona $G$ et al (2012) Identification and management of poor response to growth-promoting therapy in children with short stature. Clin Endocrinol (Oxf) 77:169-181

3. Savage MO, Burren CP, Rosenfeld RG (2010) The continuum of growth hormone-IGF-I axis defects causing short stature: diagnostic and therapeutic challenges. Clin Endocrinol 72:721-728

4. Migliaretti G, Ditaranto S, Gulot C, Vannelli S, Matarazzo P, Cappello $\mathrm{N}$ et al (2018) Long-term response to recombinant human growth hormone treatment: a new predictive mathematical method. J Endocrinol Investig 41:839-848

5. Osterberg Osterberg L, Blaschke T (2005) Adherence to medication. N Engl J Med 353:487-497

6. Oyarzabal M, Aliaga M, Chueca M, Echarte G, Ulied A (1998) Multicentre survey on compliance with growth hormone therapy: what can be improved? Acta Paediatr 87:387-391

7. Smith S, Hindmarsh P, Brook C (1993) Compliance with growth hormone treatment - are they getting it? Arch Dis Child 68:91-93

8. Bagnasco F, Di Iorgi N, Roveda A, Gallizia A, Haupt R, Maghnie M (2017) Prevalence and correlates of adherence in children and adolescents treated with growth hormone. A multicenter Italian study. Endocr Pract 23:929-941

9. Rosenfeld R, Bakker B (2008) Compliance and persistence in pediatric and adult patients receiving growth hormone therapy. Endocr Pract 14:143-154

10. Aydin B, Aycan Z, Siklar Z et al (2014) Adherence to growth hormone therapy: results of a multicenter study. Endocr Pract 20:46-51

11. Kapoor R, Burke S, Sparrow S, Hughes I, Dunger D, Ong K, Acerini C (2008) Monitoring of concordance in growth hormone therapy. Arch Dis Child 93:147-148

12. Cutfield WS, Derraik JG, Gunn AJ, Reid K, Delany T, Robinson E, Hofman PL (2011) Non-compliance with growth hormone treatment in children is common and impairs linear growth. PLoS One 6:e16223

13. Fisher BG, Acerini CL (2013) Understanding the growth hormone therapy adherence paradigm: a systematic review. Horm Res Paediatr 79:189-196
14. Desrosiers P, O'Brien F, Blethen S (2005) Patient outcomes in the GH monitor: the effect of delivery device on compliance and growth. Pediatr Endocrinol Rev 2:327-331

15. Dahlgren J, Veimo D, Johansson L, Bech I (2007) Patient acceptance of a novel electronic auto-injector device to administer recombinant human growth hormone: results from an open-label, user survey of everyday use. Curr Med Res Opin 23:1649-1655

16. Bozzola M, Colle M, Halldin-Stenlid M, Larroque S, Zignani M (2011) Treatment adherence with the easypod growth hormone electronic auto-injector and patient acceptance: survey results from 824 children and their parents. BMC Endocr Disord 11:4-13

17. Loche S, Salerno M, Garofalo P, Cardinale GM, Licenziati MR, Citro $\mathrm{G}$ et al (2016) Adherence in children with growth hormone deficiency treated with r-hGH and the easypod device. J Endocrinol Investig 39:1419-1424

18. Hartmann K, Ittner J, Muller-Rossberg E, Schonau E, Stephan R, Ullrich KP, Hoppe B, Ramseger R, Bramswig J (2013) Growth hormone treatment adherence in prepubertal and pubertal children with different growth disorders. Horm Res Paediatr 80:1-5

19. Koledova E, Stoyanov G, Ovbude L, Davies PSW (2018) Adherence and long-term growth outcomes: results from the easypod connect observational study (ECOS) in paediatric patients with growth disorders. Endocr Connect 7:914-923

20. Lass N, Reinehr T (2015) Low treatment adherence in pubertal children treated with thyroxine or growth hormone. Horm Res Paediatr 84:240-247

21. Bakker B, Frane J, Anhalt R, Lippe B, Rosenfeld RG (2008) Height velocity targets from the national cooperative growth study for first-year growth hormone responses in short children. J Clin Endocrinol Metab 93:352-357

22. Ranke MB, Lindberg A, On Behalf of the Kigs International Board (2010) Observed and predicted growth responses in prepubertal children with growth disorders: guidance of growth hormone treatment by empirical variables. J Clin Endocrinol Metab 95:1229-1237

23. Di Iorgi N, Morana G, Allegri AME, Napoli F, Gastaldi R, Calcagno A, Patti G, Loche S, Maghnie M (2016) Clasical and non-classical causes of GH deficiency in the paediatric age. Best Pract Res Clin Endocrinol Metab 30:705-736

24. www.agenziafarmaco.gov/content/note-aifa

25. Van Dommelen P, Koledova E, Wit JM (2018) Effect of adherence to growth hormone treatment on 0-2 year catch-up growth in children with growth hormone deficiency. PLoS One. https:// doi.org/10.1371/journal.pone.0206009

Publisher's Note Springer Nature remains neutral with regard to jurisdictional claims in published maps and institutional affiliations. 